\title{
Por que o Jogo: a contribuição do CEFD/UFSM na vida acadêmica
}

\author{
Why the Game: the CEFD/UFSM's contribution in academic life \\ Por qué el juego: la contribución del CEFD / UFSM en la vida académica
}

Fernanda Stein ${ }^{\mathrm{I}}$, Elizara Carolina Marin ${ }^{\mathrm{II}}$

\begin{abstract}
Resumo
Este artigo trata de uma trajetória acadêmica em Educação Física que inicia e se consolida no Centro de Educação Física e Desporto da Universidade Federal de Santa Maria. Destaca o envolvimento com a produção de pesquisas da iniciação científica à pós-graduação, organização de eventos nacionais e internacionais pela via da participação no Grupo de Pesquisa em Lazer e Formação de Professores, em específico, acerca do tema Jogo. Mostra as várias possibilidades de crescimento e qualificação profissional e humano que a instituição proporciona para aqueles que nela trilham sua jornada acadêmica e compartilham parte de suas vidas.
\end{abstract}

Palavras-chave: Jogo; Trajetória acadêmica; Pesquisa; Educação Física

\begin{abstract}
This article focuses on an academic trajectory in Physical Education that begins and consolidates at the Centro de Educação Física e Desportos of the Universidade Federal de Santa Maria. It highlights the involvement with the production of research for scientific initiation, postgraduate, organization of national and international events through participation in the Grupo de Pesquisa em Lazer e Formação de Professores, specifically, on the theme of Games. It shows the various possibilities for professional and human growth and qualification that the institution provides for those who follow their academic journey and share part of their lives.
\end{abstract}

Keywords: Game; Academic trajectory; Research; Physical Education

${ }^{\text {I } U n i v e r s i d a d e ~ F e d e r a l ~ d o ~ P a m p a ~-~ U N I P A M P A ~-~ E n d e r e c ̧ o: ~ B R ~} 472$ - Km 585, CEP: 97501-970, Cidade: Uruguaiana, RS - e-mail: fernandastein.ef@gmail.com

II Universidade Federal da Paraíba - UFPB - e-mail: elizaracarol@yahoo.com.br 


\section{Resumen}

Este artículo trata de una trayectoria académica en Educación Física que se inicia y se consolida en el Centro de Educação Física e Desportos de la Universidade Federal de Santa Maria. Destaca el involucramiento con la producción de investigación desde la iniciación científica hasta los estudios de posgrado, organización de eventos nacionales e internacionales a través de la participación en el Grupo de Pesquisa em Lazer e Formação de Professores, específicamente, en la temática Juego.Muestra las diversas posibilidades de crecimiento y calificación profesional y humana que la institución brinda a quienes recorren su trayectoria académica y comparten parte de su vida en ella.

Palabras clave: Juego; Trayectoria académica; Investigación; Educación Física

\section{Introdução}

"Que a importância de uma coisa não se mede com fita métrica
nem com balanças nem barômetros etc. Que a importância de
uma coisa há que ser medida pelo encantamento que a coisa
produza em nós."

(MANOEL DE BARROS, 2006, p. 23)

A escolha de um tema de estudo não é resultado de um acaso. Mills (1975) reconhece a pesquisa como parte íntima da vida do pesquisador. Tampouco deve vir de fora, imposto ou doado, mas sim "deve ser uma conquista de dentro, construção própria”, conforme salienta Demo (2003, p.22).

É com esse olhar que pretendo, nesse artigo, expor minha trajetória acadêmica e, principalmente, as escolhas feitas no decurso cuja contribuição fundante advém da formação inicial e da pós-graduação em nível de mestrado realizadas no Centro de Educação Física e Desportos (CEFD) da Universidade Federal de Santa Maria (UFSM).

Em 2006 ingressei no curso de Educação Física - Licenciatura e, em 2009, inseri-me no Grupo de Pesquisa em Lazer e Formação de Professores (GPELF), coordenado por minha orientadora, professora Elizara Carolina Marin e pelo professor João Francisco Magno Ribas. Desde então tenho estudado e pesquisado sobre os temas Jogo e Jogo Tradicional.

No decorrer do meu percurso acadêmico mostrou-se pertinentemente, a ponto de transformar-se em inquietação, a seguinte pergunta: por que pesquiso Jogo?

Obviamente, justificativas sociais, considerando a importância do tema não faltam. Ou seja, o jogo é uma manifestação universal e cultural. Universal no sentido de que está presente e traduz a necessidade universal humana da diversão, do prazer e da festa. Para Huizinga (2010), o jogo encerra um sentido em si mesmo, transcende as necessidades materiais imediatas da vida. Na essência do jogo está a fruição intensa, 
incerta e desafiadora. E, cultural, no sentido de que é construído no interior das culturas dos povos. Assim, segundo Caillois (1990), os jogos expressam os costumes, as formas de se organizar em sociedade e assumem características a partir do contexto e das relações sociais estabelecidas.

As relações entre jogo e contextos sociais sempre foram ponto de análise, revisitadas a todo instante, a fim de não esvaziar o sentido social dos estudos. Porém, que sentido tem o Jogo na minha vida acadêmica e pessoal?

\section{Oportunidades em Grupo de Pesquisa e na Iniciação Científica}

Em 2009, em meu primeiro ano integrada ao GPELF, inseri-me na pesquisa "Diagnóstico das manifestações de esporte e lazer do campo e da cidade no estado do Rio Grande do Sul" e fui a campo. Com roteiro de entrevista em mãos, explorei parte do universo de manifestações da cultura expressas em um pequeno município do interior do estado. Tiro de laço, Ginete, Vaca parada, Bocha, Truco ${ }^{2}$, danças locais, entre outras manifestações, vestiram-se (ou despiram-se) de maneira que eu nunca havia presumido. Retornei do campo com a certeza de que gostaria de estudar mais sobre diferentes manifestações da cultura ligadas ao lazer, afinal elas faziam sentido na vida daquele grupo que pesquisei; o jogo era parte da vida dessas pessoas.

Outrossim, os coordenadores do GPELF mantinham contato e parcerias com pesquisadores brasileiros, estrangeiros latino-americanos e europeus expoentes ${ }^{3}$ acerca do tema Jogo Tradicional, o que contribuía para que a temática fosse fortalecida no grupo através de reuniões de estudo, pesquisas de iniciação científica, Trabalhos de Conclusão de Curso (TCCs), dissertações, projetos de extensão e de ensino.

Encantada pela temática, minha pesquisa de TCC teve o objetivo de compreender o Jogo Tradicional nos referenciais curriculares dos estados brasileiros e as suas propostas para o componente curricular de Educação Física. Identifiquei a presença do Jogo Tradicional na maior parte dos documentos. Entretanto, a sistematização desse conhecimento restringia-se, na maioria das vezes, aos primeiros anos do ensino fundamental e, ainda, na perspectiva de recurso metodológico para a preparação desportiva, longe de ser

\footnotetext{
${ }^{1}$ Pesquisa financiada pelo Ministério do Esporte/Secretaria Nacional de Desenvolvimento de Esporte e de Lazer/Centro de Desenvolvimento do Esporte e Recreativo e de Lazer (ME/SNDE/REDE CEDE), sob a coordenação dos pesquisadores Elizara Carolina Marin e João Francisco Magno Ribas, que objetivou realizar um diagnóstico detalhado das manifestações de esporte e lazer do campo e da cidade da região central do Rio Grande do Sul considerando a identificação, a descrição e a inter-relação com o contexto sociocultural.

${ }^{2}$ Jogos característicos do estado do Rio Grande do Sul, consideradas tradições da cultura gaúcha.

${ }^{3}$ Dentre eles, Pierre Normando Gomes-da-Silva (Brasil); Soraya Chung Saura (Brasil), Maria Beatriz Rocha Ferreira (Brasil), Carolina Poblete Gálvez (Chile), Nelson Medina Puerto (Honduras), Armando Padilla Alonso (México), Pere Lavega Burgués (Espanha) e Pierre Parlebas (França).
} 
abordado como produção cultural humana. Percebi, então, que a Educação Física tinha ainda muito a avançar. Nesse período, surgiram minhas primeiras angústias sobre como poderia contribuir com o tema.

No decorrer dos anos de 2010 e 2011, participei como bolsista de iniciação científica na pesquisa "Diagnóstico dos Jogos Tradicionais do campo e da cidade no estado do RS" agora com olhar voltado aos Jogos de alguns grupos étnicos característicos no estado, como o italiano, o alemão, o indígena e o português.

Os conceitos de Jogo e Jogo Tradicional, estudados no grupo, começaram a fazer algum sentido para mim com a imersão no campo, com as entrevistas e com as observações. Em uma equipe constituída por cinco estudantes de iniciação científica e pelos dois coordenadores do GPELF, viajamos para cidades expressivas de cada grupo social no RS. Lá permanecíamos alguns dias buscando elementos que nos levassem até os jogos, entrevistando jogadores, estabelecendo contatos, fotografando, filmando, buscando registros para costurarmos as teias que permitiam compreender os jogos no interior daquelas culturas. Esta pesquisa gerou o primeiro livro do qual participei como bolsista, Jogo Tradicional e Cultura (Marin; Ribas, 2013), ilustrado abaixo na Figura 1.

Figura 1 - Capa do livro "Jogo Tradicional e Cultura"

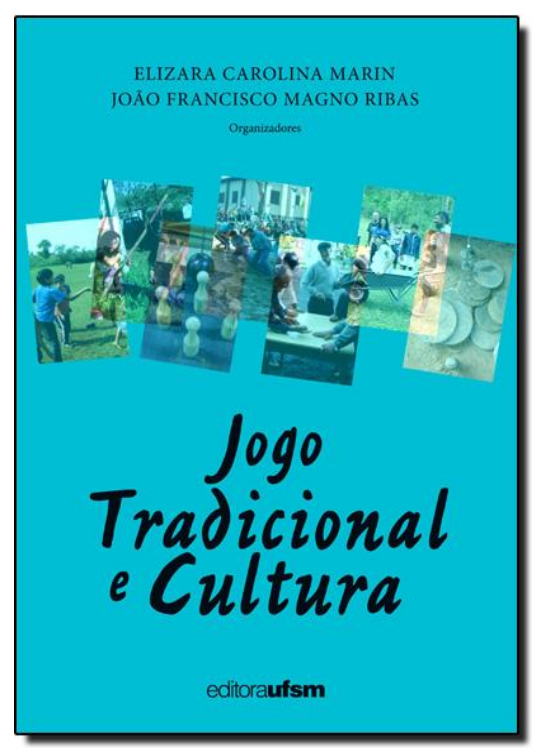

Fonte: Marin e Ribas (2013)

\footnotetext{
${ }^{4}$ Pesquisa financiada pelo Ministério do Esporte/Secretaria Nacional de Desenvolvimento de Esporte e de Lazer/Centro de Desenvolvimento do Esporte e Recreativo e de Lazer (ME/SNDE/REDE CEDE), sob a coordenação dos pesquisadores Elizara Carolina Marin e João Francisco Magno Ribas, que objetivou identificar, analisar e caracterizar os jogos tradicionais de diferentes etnias no estado de RS e as relações com o contexto sociocultural a fim de contribuir para a memória, a difusão cultural, o desenvolvimento de ações educativas e para a democratização das políticas públicas.
} 
Com a participação neste projeto, tive a oportunidade de estudar os principais autores sobre o tema, ler sobre pesquisa de campo, aprender sobre os processos históricos de constituição desses grupos no RS, entrevistar e transcrever, fotografar, filmar, preencher fichas sobre lógica interna e externa ${ }^{5}$ de alguns dos jogos identificados e, ainda que timidamente, fazer algumas sínteses de pesquisa. Além disso, os sentimentos de pertencimento e de estranhamento acompanharam-me nesse processo de imersão em grupos sociais eminentemente rurais, principalmente ao estudar as etnias alemã e italiana.

\section{Quando a Pesquisa encontra a Vida}

Então, pesquisa e vida se mesclaram. A descendência alemã e rural no RS, na qual o jogo está presente fortemente no dia a dia, na educação dos filhos e netos e nos encontros aos finais de semana ecoou no percurso das pesquisas.

Entrevistar um senhor de 80 anos de idade nas vestes típicas alemãs, com sotaque "carregado", despontou a memória de meu avô em dia de festa na Sociedade ${ }^{6}$. Ouvir o som da bola do bolão tombando os pinos, rememorou os dias em que assistia o grupo de bolão de mulheres do qual minha avó fazia parte. Observar a concentração dos jogadores de canastra, lembrou-me dos meus tios nas rodas de carteado e eu aprendiz do jogo, sentada ao lado de minha avó, de minha mãe ou de minha irmã que, gradualmente, instruíam-me sobre o funcionamento da canastra. Aos poucos, em minha família, filhos, netos e bisnetos iam sendo inseridos em um universo de manifestações que proporcionavam um tempo e espaço de diversão e de construção de identidade. E assim foi no campo pesquisado: eu sentia-me parte de uma memória e de um grupo do qual, em sentido restrito, eu não pertencia, mas que, de alguma maneira, estavam inscritos em mim, como uma memória coletiva.

Embora esses sentimentos já estivessem presentes desde meu primeiro interesse acadêmico sobre o tema, eles se apresentavam de maneira difusa. Apenas quando questionei sobre o sentido do Jogo na minha vida, esses elementos tomaram forma mais clara. Larrosa Bondía (2002), em notas sobre os saberes da experiência, revela que pensar não é somente racionalizar e calcular, mas é, especialmente, dar sentido ao que somos e ao que nos acontece. Ao instigar sobre quando, como e por quê o jogo está presente nos meus interesses acadêmicos, não há como desvinculá-lo da minha própria trajetória de vida.

\footnotetext{
${ }^{5}$ Conceitos abarcados na Teoria da Ação Motriz, desenvolvida pelo pesquisador francês Pierre Parlebas. Sobre o tema, ver a obra de Parlebas (2001), "Juegos, deportes y sociedades: léxico de praxiología motriz".

${ }^{6}$ Também denominada Associação Esportiva. As Sociedades constituíram-se como espaço onde a população compartilhava propósitos, costumes e preocupações em comum, e tiveram papel fundamental na reconstrução social e cultural dos imigrantes, especialmente alemães e italianos, que chegaram ao sul do Brasil no decorrer do século XIX.
} 
As recordações das pessoas mais importantes em minha trajetória estão associadas ao Jogo. Lembranças relacionadas aos meus pais são aquelas nas quais jogávamos $\mathrm{General}^{7}$ e Pontinho ${ }^{8}$; ensinavamme a construir pipa feita de saco de lixo e casinhas com caixas de papelão; e encorajavam-me a andar de bicicleta ladeira abaixo. As dos meus avós estão associadas aos encontros para rodadas de canastra, aos grupos de bolão ${ }^{9}$, às reuniões que aconteciam semanalmente para jogar Víspora ${ }^{10}$. Na Canastra ou na Víspora, o momento mais esperado por mim era aquele em que alguém se ausentava, dando a chance de minha ascensão de observadora à jogadora. As memórias relacionadas aos meus primos são as de construções de casas em árvores, de escorregar cerro abaixo em folha de papelão, de ensinar aos mais novos os jogos da família. E às dos meus amigos estão conectadas às brincadeiras de Sapata (Amarelinha) nas calçadas do bairro, de "se esconder" e de "pega-pega" nas ruas, às corridas de bicicleta e de carrinho de lomba na cidade. Em síntese, o jogo sempre teve, para mim, significado substancial: de educação, de diversão, de pertencimento e de liberdade. Ele é parte da minha vida, seja dentro ou fora da Academia.

\section{Experiências na Pós-Graduação e em Eventos Internacionais}

Na sequência de minha formação o Jogo fez-se como desejo de vida e como objeto de pesquisa. No Mestrado em Educação Física - CEFD/UFSM - (2012-2014), pesquisei sobre os sentidos atribuídos aos jogos tradicionais no contexto da colonização italiana no Rio Grande do Sul, compreendi que o jogo tem sentido na vida de quem joga quando assumido em seu caráter livre, informal, casual, simples, imprevisível, desafiador, provocador, tenso e, fundamentalmente, quando possibilita exteriorizar a interioridade. Em outras palavras, quando materializa a interioridade. E só pode ser compreendido em sua dinamicidade, como parte da cultura viva.

Esse processo de acadêmico desencadeou aprovação na pós-graduação em nível de doutorado, na Universidade Federal de Pelotas (UFPel). Os laços com o CEFD-UFSM permaneceram, tanto pela continuidade da orientação da professora Elizara (colaboradora no Programa de Pós-Graduação em Educação Física da UFPel) quanto porque as várias ações e discussões relacionadas ao Jogo aconteciam com maior expressão no CEFD. Investiguei o Jogo no contexto da cidade, a partir de Coletivos Culturais que atuam em espaços públicos na cidade de São Paulo. Identifiquei que no cerne das ações desses

\footnotetext{
${ }^{7}$ Também conhecido como Yam, jogo de dados cujo objetivo é marcar o maior número de pontos, através de algumas combinações de resultados nos dados.

${ }^{8}$ Consiste em preencher uma folha de papel com pontos à caneta. Cada jogador deve unir um ponto ao outro, na horizontal ou na vertical, trançando uma linha entre eles. Ao conseguir unir os quatro lados e fechar um quadrado, o jogador ganha um ponto.

${ }^{9}$ Similar ao Boliche, cujo objetivo é derrubar o maior número de pinos com a bola.

${ }^{10}$ Jogo conhecido atualmente como Loto ou Bingo.
} 
coletivos, está a defesa da conexão entre a cidade e a dimensão lúdica nos seres humanos, de uma cidade mais brincante sob a perspectiva do Jogo.

Para além da pesquisa, no ano de 2013, por convite de minha orientadora e por curiosidade, inserime, inicialmente como ouvinte e observadora, em um movimento de consolidação de uma rede internacional de contato, pesquisa e ações sobre jogos tradicionais do Continente Americano. Nesse mesmo ano, viajei para San Marcos/Santa Barbara - Honduras, onde aconteceu o II Congreso Panamericano de Juegos Tradicionales y Deportes, ocasião na qual a Associação Pan-Americana de Jogos e Esportes Autóctones e Tradicionais (APJDAT) ${ }^{11}$ foi criada, contando com a representação de sete países (Argentina, Brasil, Chile, Guatemala, Honduras, México e Panamá). Participei das apresentações de trabalho, das reuniões e das discussões sobre a criação da associação e do Festival Nacional de Juegos Tradicionales, que reúne anualmente milhares de pessoas em San Marcos/Santa Barbara. Durante um dia inteiro de festival, estive imersa em um contexto de jogos que variavam desde os conhecidos pião e bolita (bolinha de gude) até jogos de civilizações Maia e Mapuche ${ }^{12}$, como o Juego de la Pelota Maya (denominado Chaaj $)^{13}$ e o Palin $^{14}$, que carregam consigo ritos e valores ancestrais desses povos.

Ao final de 4 dias de Encontro, com a APJDAT constituída, decidiu-se que o próximo país a sediar o evento seria o Brasil, sob a coordenação da professora Elizara Carolina Marin. Na viagem de retorno do evento, já rascunhávamos as primeiras ideias para a organização. Nesse instante, percebi o quanto eu também já estava envolvida com esse movimento e que essa seria uma grande oportunidade de contribuir e aprender sobre o universo dos jogos.

Participei da organização do III Encontro Pan-Americano de Jogos e Esportes Autóctones e Tradicionais (III EPJAT) financiado pela REDE CEDES e pelo Conselho Nacional de Desenvolvimento Científico e Tecnológico (CNPq).

Estudantes integrantes do GPELF coordenados pela professora Elizara compuseram a comissão organizadora do evento internacional que ocorreu em 2015 na cidade de Palmas/Tocantins. Nesse processo, participei ativamente na coordenação geral de todas as etapas, desde a escolha da cidade brasileira sede ${ }^{15}$

\footnotetext{
${ }^{11}$ Para mais informações sobre a APJDAT ver https://apjdat8.webnode.com/

${ }_{12}$ Mapuches, povo indígena da região centro-sul do Chile e do sudoeste da Argentina.

${ }^{13}$ Jogado ao longo de mais de 3000 anos pelos povos da Mesoamérica. Consiste em arremessar uma bola de borracha entre os jogadores fazendo-a atravessar um aro de pedra. É proibido usar as mãos e os pés. Os jogadores só podem arremessar a bola usando as coxas, os braços e os quadris. Foram encontrados campos do jogo de bola mesoamericano em diferentes culturas da América do Norte e Central. A maior quantidade concentra-se no México, onde existem cerca de 1500 campos de jogo de bola o que evidencia a importância dessa atividade entre as culturas dessa região.

${ }^{14}$ Jogo similar ao hóquei na grama - a diferença mais marcante consiste na dimensão do campo - medindo aproximadamente 200m x $12 \mathrm{~m}$. O objetivo é levar a bola até a meta utilizando bastões.

${ }^{15}$ A cidade de Palmas foi escolhida para sediar o III EPJAT pois no mesmo período e ano ela também seria sede dos I Jogos Mundiais dos Povos Indígenas, possibilitando a aproximação de ambos eventos, facultando o diálogo e fortalecendo o tema comum: os jogos tradicionais dos diferentes povos.
} 
até a construção da programação, o aluguel das estruturas, o estabelecimento de parcerias, a coordenação dos espaços e das demandas durante os dias de evento até o relatório final entregue ao CNPq, referente aos recursos angariados para a consecução do Encontro.

Além da organização de toda infraestrutura que um evento exige, cabia a nós o mapeamento de grupos de pesquisa, jogadores, artesãos, coletivos, enfim, pessoas no Brasil e no continente americano engajadas com a temática, a fim de ampliar a rede internacional recém consolida em Honduras. Posso dizer que de todas as funções que exerci na organização, a mais prazerosa foi esta. Fiquei responsável por encontrar e contatar pessoas dos países do continente americano. Já existiam alguns contatos dos eventos anteriores, porém conseguimos estabelecer diálogo com pessoas de 19 países ${ }^{16}$ que partilhavam dos mesmos interesses e eram movidas pelos mesmos encantamentos pelo Jogo, pelos mesmos interesses em agir e trabalhar em rede, em estreitar relações e ampliar conhecimentos. Mais uma vez alarguei meu horizonte sobre o tema.

O III EPJAT teve resultados significativos: contou com representantes de 9 países do Continente Americano (Argentina, Chile, Colômbia, Guadalupe, Haiti, Honduras, México, Panamá e Peru) ${ }^{17}$; de 21 estados do Brasil, entre jogadores, artesãos, artistas, professores da Educação Básica, graduandos e professores universitários; de 7 Associações e Coletivos Culturais; de 7 Museus ligados aos Brinquedos e aos Jogos Tradicionais; e do Ministério do Esporte. O Encontro ajudou a impulsionar um movimento de valorização cultural e de investigação e difusão do conhecimento sobre os jogos e alçou a um outro patamar as discussões, dando visibilidade ao tema no contexto do Brasil e da América.

Também fruto deste evento, houve a organização de dois livros: 1. Jogos Autóctones e Tradicionais de Povos da América Latina (Figura 2), momento especial para minha experiência profissional, quando participei pela primeira vez da organização de um livro e da publicação de um capítulo derivado de minha dissertação de mestrado e onde tive a oportunidade de dialogar com autores renomados na América Latina sobre o tema. E 2. Jogos Tradicionais e Educação Física Escolar: experiências concretas e sedutoras (Figura 3), organizado por Marin e Gomes-da-Silva (2016) que traz contribuições inspiradoras para o desenvolvimento do tema no contexto escolar.

\footnotetext{
${ }^{16}$ Argentina, Brasil, Bolívia, Canadá, Chile, Colômbia, Costa Rica, Cuba, Estados Unidos, Guadalupe, Guatemala, Haiti, Honduras, México, Nicarágua, Panamá, Peru, Uruguai, Venezuela.

${ }^{17}$ Poderia ter havido representações de muitos outros países com os quais fizemos contato; todavia, a situação econômica e/ou a falta de apoio governamental desses países inviabilizou sua presença nos jogos.
} 
Figura 2 - Capa do livro "Jogos Autóctones e Tradicionais de Povos da América Latina"

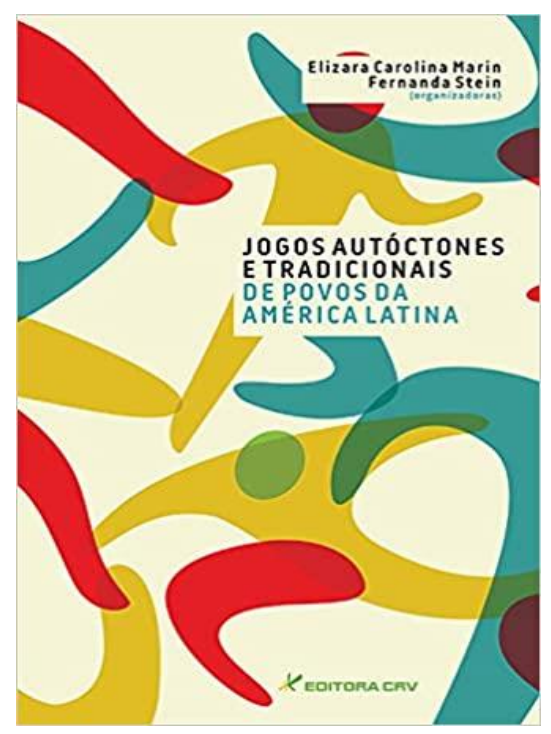

Fonte: Marin e Stein (2015)

Figura 3 - Capa do livro "Jogos Tradicionais e Educação Física Escolar: experiências concretas e sedutoras"

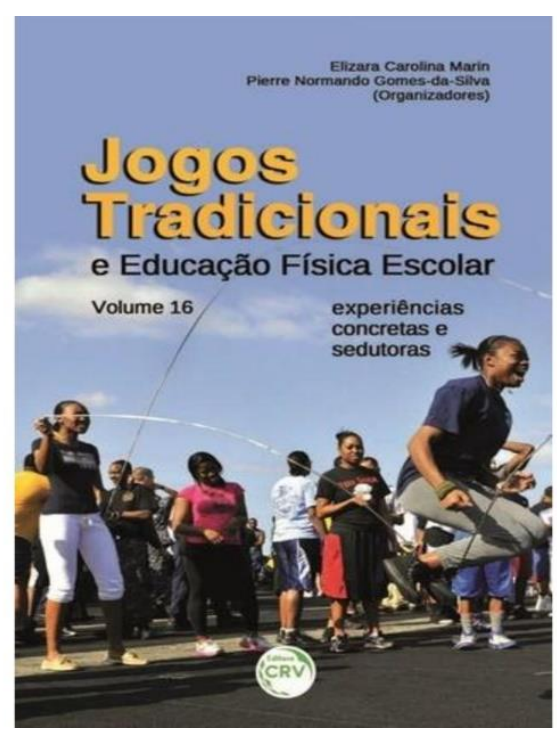

Fonte: Marin e Gomes-da-Silva (2016)

Além das produções dos livros, ao final do III EPJEAT, houve a construção do documento denominado "Declaração de Palmas", elaborada pelos participantes, sugere e recomenda o reconhecimento e o fomento de políticas nacionais para o fortalecimento da cultura lúdica autóctone e tradicional aos países membros da Organização das Nações Unidas para a Educação, a Ciência, e a Cultura (UNESCO). Como forma de divulgação e de união de forças, a Declaração foi entregue em mãos aos líderes indígenas Marcos 
e Carlos Terena ${ }^{18}$, durante os Jogos Mundiais dos Povos Indígenas, que estavam acontecendo na mesma cidade e data de nosso evento. Foi um momento ímpar na minha trajetória de vida e acadêmica. Durante a solenidade de entrega do documento, fui surpreendida pelo convite de ler a Declaração de Palmas. Tive a oportunidade de ler não apenas recomendações, mas aspirações e anseios coletivos, para representantes dos 9 países presentes no III EPJAT e de líderes indígenas com histórias de luta em território nacional e internacional, reunidos naquele tempo e espaço pela defesa e visibilidade dos jogos autóctones e tradicionais.

Ao final do evento surgiu a necessidade de construção de uma rede nacional ${ }^{19}$ a fim de fortalecer e de colocar em marcha novas ações e de atuar em parcerias no país; e a organização do I Encontro Brasileiro de Jogos Tradicionais e Autóctones.

No decorrer dos anos de 2016 e 2017 participei dessas duas ações. O I Encontro Brasileiro aconteceu no CEFD/UFSM, em outubro de 2017, com palestras, exposições de jogos, reuniões com os participantes para elaboração e síntese de proposições em torno dos jogos no Brasil; e com o Festival de Jogos Tradicionais que, sob meu ponto de vista, ilustrou o sentido de todas as ações com as quais estivera envolvida até então.

Em parceria com a Secretaria Municipal de Educação de Santa Maria, reunimos mais de 500 crianças e jovens (entre 7 e 15 anos) de 6 escolas municipais, transformando o festival em um grande jogo. Previsto para acontecer em espaço amplo, arborizado e aberto, teve que ser transferido para um dos ginásios do CEFD, em virtude da chuva. Todas as 22 oficinas tiveram que ser reajustadas ao novo local. Havíamos planejado a organização das crianças em grupos pequenos, guiados por seus professores, com sistema de rotação dos grupos entre as oficinas. Após receber o último ônibus com os estudantes e professores participantes do Festival, retornei ao ginásio e fui surpreendida. Não havia sequer sinal dos grupos divididos previamente. Tampouco havia uma desorganização.

Parei por um instante para compreender o que estava acontecendo. As 500 crianças e adolescentes haviam se reorganizado a partir de seus interesses e curiosidades. Uma nova dinâmica de organização e de regras para o Festival se configurou. Estudantes passavam empurrando outros em cima de Carrinhos de Rolimã; ouvia-se os estalos das Quengas de Coco batendo no chão, onde outro grupo disputava corrida de tamancos; aqueles que gostavam de desafios e problemas de lógica, formaram um semicírculo ao redor das mesas dos Jogos de Raciocínio; os Jogos de Tabuleiro de diversos lugares do mundo encantavam quem colocasse os olhos neles; atravessar o ginásio de uma ponta a outra tornava-se questão de honra para quem

\footnotetext{
${ }^{18}$ Líderes pertences à etnia indígena Xané, também conhecida como Terena. São idealizadores dos Jogos dos Povos Indígenas, um dos maiores encontros sobre a cultura lúdica indígena na América. Também foram articuladores e representantes na organização do I Jogos Mundiais dos Povos Indígenas.

${ }^{19}$ Atualmente denominada Rede Brasileira de Jogos Tradicionais e Autóctones.
} 
cruzava pelo Roda e Trava. Uma fila formou-se em frente aos pinos de Bolão; um grupo de curiosos assistia atento à construção de Pipas. Via-se de longe um laço no ar e, segurando a corda, um jovem boiadeiro mirando o par de chifres da Vaca Parada; no centro do ginásio, uma corda estendida no chão convidava dois grupos para o Cabo de Força. Por um instante, congelei a imagem e vi a famosa pintura do artista flamengo Pieter Bruegel (Jogos Infantis -1560$)^{20}$ sendo reconstruída dentro de um ginásio poliesportivo. Não havia tempo a perder, a manhã era curta e cada minuto dela era preenchido por gestos, gritos, silêncios, atenção, curiosidade, superação, delicadeza, força, surpresas, aprendizado, emoções e, acima de tudo, pelo riso.

Naquela manhã, reconheci materializado o sentido de toda minha trajetória acadêmica. Algumas premissas que eu já identificava como falsas, bem como estudos sobre o Jogo já denunciavam (FRIEDMANN, 2005; CARVALHO et al., 2003; MEIRELLES, 2015; MARIN; STEIN, 2015; MARIN; GOMES-DA-SILVA, 2016; SAURA, 2014), foram comprovadamente desmentidas: não era verdade que, na atualidade, criança não sabe mais brincar; que jogo é exclusivo da infância; que adolescentes não se interessam por jogos tradicionais; que os jogos ditos "antigos" tinham se tornado obsoletos diante das possibilidades das novas tecnologias e de formas de diversão virtuais/digitais. No Festival de Jogos Tradicionais, realizado no CEFD/UFSM, nenhum celular defraudou o tempo daquelas crianças e adolescentes, seduzidas pelo conjunto de jogos que lhes foram apresentados.

\section{Marcas e sentidos do CEFD/UFSM na minha vida}

Hoje, depois de 14 anos de meu primeiro contato com o CEFD, faço parte do corpo docente do Curso de Educação Física da Universidade Federal do Pampa (Unipampa), o que em grande medida só foi possível porque tive a oportunidade de fazer parte das experiências relatadas no decorrer desse texto. Sou grata ao CEFD, ao GPELF e a todos professores e colegas com quem pude conviver, aprender e desenvolver conhecimentos e valores imprescindíveis à profissão de Professora de Educação Física.

O aqui exposto nestas linhas é uma síntese que diz da relação profunda e profícua do Centro de Educação Física e Desportos na minha vida e na formação acadêmica. Diz de um coletivo docente e de Grupos de Pesquisas atuantes e comprometidos com o ensino, com a pesquisa e com a extensão. Todavia, estes escritos, nem de longe podem resumir os sentidos produzidos em mim e quiçá do coletivo de discentes da graduação e da pós-graduação que nesses 50 anos passaram pelo CEFD. ${ }^{20}$ A tela mostra 250 figuras humanas brincando nas ruas, no século XVI, com cerca de 80 jogos, muitos deles conhecidos, como pernas de
pau, roda, pular corda, rodar aros (roda e trava), cavalo de pau, cata-vento, pular carniça, boneca, pião, cavalinho, cabo de força, entre outros. 


\section{Referências}

CAILLOIS, Roger. Os jogos e os homens: a máscara e a vertigem. Lisboa: Cotovia, 1990.

CARVAlHO, Ana Maria Amélia, et al. (Orgs.) Brincadeira e Cultura: viajando pelo Brasil que brinca. São Paulo: Casa do Psicólogo, 2003.

DEMO, Pedro. Pesquisa: princípio científico e educativo. 10. ed. São Paulo: Cortez, 2003.

FRIEDMANN, Adriana. O universo simbólico da criança: olhares sensíveis para a infância. Petrópolis: Vozes, 2005.

HUIZINGA, Johan. Homo Ludens: o jogo como elemento da cultura. 6. ed. São Paulo: Perspectiva, 2010.

LARROSA BONDÍA, Jorge. Notas sobre a experiência e o saber de experiência. Revista Brasileira de Educação, n. 19, p. 20-28, 2002.

MARIN, Elizara Carolina; RIBAS, João Francisco Magno. Jogo Tradicional e Cultura. Santa Maria: Editora UFSM, 2013.

MARIN, Elizara Carolina; STEIN, Fernanda. Jogos Autóctones e Tradicionais de Povos da América Latina. Curitiba: Editora CRV, 2015.

MARIN, Elizara Carolina; GOMES-DA-SILVA, Pierre Normando. Jogos Tradicionais e Educação Física Escolar: experiências concretas e sedutoras. Curitiba: Editora CRV, 2016.

MEIRELLES, Renata. Território do brinca: diálogo com escolas. São Paulo: Instituto Alana, 2015.

MILLS, Wright. A Imaginação Sociológica. Rio de Janeiro: Zahar, 1975.

PARLEBAS, Pierre. Juegos, deporte y sociedade: Léxico de Praxiología Motriz. Barcelona: Paidotribo, 2001.

SAURA, Soraia Chung. Sobre bois e bolas. In.: SAURA, Soraia Chung; ZIMMERMANN, Ana.Cristina (Orgs). Jogos Tradicionais. São Paulo: Laços. 2014. p. 165-188.

\section{Como citar este artigo}

STEIN, F; MARIN, E.C. Por que o Jogo: a contribuição do CEFD/UFSM na vida acadêmica. Revista Kinesis, Santa Maria, Dossiê CEFD 50 anos, p.1-12, 2020.

*O presente trabalho não contou com apoio financeiro de nenhuma natureza para sua realização. 